THE SMART WAY TO IMMEDIATE RESTORATIONS

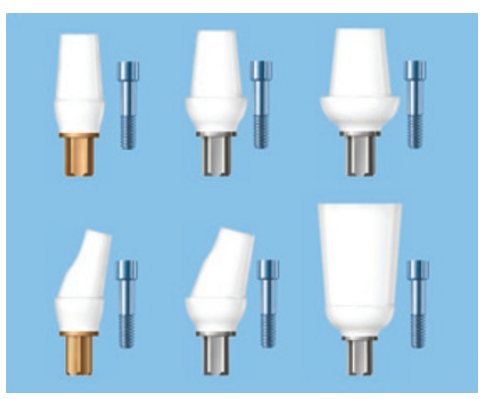

bredent medical has introduced new prefabricated SKY elegance abutments. The SKY elegance abutment combines both the properties of a temporary and a definitive abutment and allows drastic reduction of the treatment steps. Maximum protection of the gingiva is guaranteed and treatment time is reduced.

The SKY elegance titanium base enables dental technicians to fabricate individual hybrid abutments made of BioHPP. The 'off-peak' material property results in a reduction of the forces on the implant and minimised stress of the bone. Furthermore the 'white shade' of BioHPP avoids dark shadows in the gingiva to ensure perfect aesthetic results. The soft tissue responds very positively to BioHPP, in particular as far as gingival attachment is concerned. These properties are now offered by six different prefabricated types of the SKY abutment.

The SKY elegance abutment can be placed immediately during surgery and a temporary restoration can be fabricated in cases of adequate primary stability. The definitive restoration can be fabricated a few weeks later and the abutment does not need to be removed. The gingiva is not traumatised. Conventional or digital procedures can be used for the impression and fabrication of crowns, so the SKY elegance abutment is perfectly suitable for the digital workflow using an intraoral scanner and CAD/CAM fabrication. As it is not necessary to screw in any gingiva formers and impression abutments, users will save time chairside and clinical results can also be improved.

www.bredent-medical.com

\title{
FROM THE BATTLEFIELD TO THE LECTURE THEATRE
}

GSK are sponsoring two lectures at this year's conference:

10 April, 12.30-1.30 pm: From the battlefield to chairside - the use of NovaMin in combatting dentine hypersensitivity. Adapted from a material that was originally invented for bone prosthetics, NovaMin is a unique desensitising agent which uses the two main constituents of hydroxyapatite to build a protective layer over and within dentine tubules. This lecture will present the history of NovaMin and how it was developed for use in oral care products.

11 April, 9.30-10.30 am: What is the acid truth? Helping you in the search for undiagnosed tooth wear. Professor David Bartlett explains the role of the Basic Erosive Wear Examination (BEWE) tool and provides guidance on patient management strategies.

Visit stand B03 to receive FREE sample boxes and to discover more about the unique technology of Sensodyne with NovaMin, as well as the Pronamel range of products which are proven to protect your patients from the effects of acid wear.

\section{EXPERIENCE UNSURPASSED MAGNIFICATION SYSTEMS}

Discover the unsurpassed quality of Carl Zeiss magnification systems at the British Dental Conference and Exhibition 2014.

The team from Nuview will be on hand showcasing its range of top quality Carl Zeiss visualisation equipment. Delegates will be amazed by the superior imaging and ergonomic advantages these products provide.

Carl Zeiss equipment such as the OPMI Pico Dental Microscope and EyeMag Smart and EyeMag Pro loupes are designed to accompany all areas of dentistry and are exclusively distributed in the UK by Nuview.

Attendees can also discover the wide variety of alcohol-free infection control solutions in Nuview's Continu range. Including equipment cleaners, surface disinfectants and hand sanitisers, Continu aids HTM 01-05 compliance and is independently tested to exceed European standards.
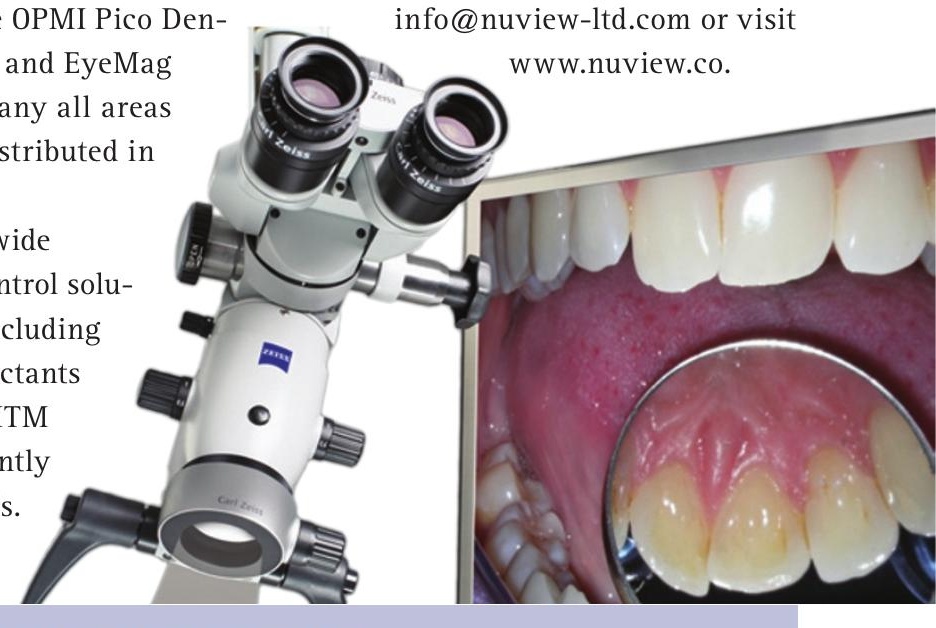

\section{EFFECTIVE COSMETIC ORTHODONTICS FOR THE GDP}

To find out how you could enhance your treatment range and grow your business, visit Intelligent Alignment Systems (IAS) on stand A39 at the British Dental Conference and Exhibition 2014.

Providing the innovative Inman Aligner, Powerprox 6 Month Braces and ClearSmile, the IAS team will show you how you can offer simple but effective cosmetic orthodontics for a wide range of patients.

Information will also be readily available on the hands-on and online training courses available, led by some of the leading professionals in the field such as Dr Rick DePaul. Ongoing support and advice is also easily accessible once the training is complete, ensuring success from your very first case.

Discover how you can use easy-to-use 3D software for effective treatment planning and successful clinical outcomes, regardless of your previous experience in the provision of cosmetic orthodontics. Visit IAS on stand A39 in Manchester.

For more information on Intelligent Alignment Systems, visit www.inmanalignertraining.com, www.6mbrace.com, and www.clearsmilealigner.com or phone 08453665477. 